\title{
A Virtual Reality Training Tool to Improve Weight-Related Communication Across Healthcare Settings
}

\author{
Fiona Quigley \\ Ulster University \\ Newtonabbey \\ Northern Ireland \\ quigley-f5@ulster.ac.uk
}

\begin{abstract}
Introduction: Discussing overweight or obesity in healthcare settings is a sensitive topic but it presents a global health challenge. Healthcare professionals (HCP) cite a lack of training and there are few studies on the practice of sensitive communication skills needed to engage patients. Using Virtual Reality (VR) as a training tool is a safe and immersive way to acquire the skills needed. Methods: This research is a mixed method 5-phase study to design, develop and test the feasibility of a VR-based training approach to improve weight-related communication in healthcare settings. The training will use a novel wizard-of-oz (WOZ) experimentation technique. Outcome: The anticipated outcome of this $\mathrm{PhD}$ is the development and feasibility testing of a VRbased training tool to improve weight-related communication with patients who are overweight and obese in healthcare settings.
\end{abstract}

Virtual reality. Digital learning. eLearning. Wizard of Oz. Human computer interaction. Health communication. Healthcare professionals. Weight management. Obesity Management.

\section{INTRODUCTION}

Overweight and obesity are chronic disease risk factors, associated with reduced life expectancy (Abdelaal et al. 2017). The global 'obesity crisis' is well documented and few countries have reduced the trend (World Obesity Federation 2019). Maintaining a weight that supports health is challenging in the current obesogenic environment, but together with food and built environment changes, healthcare professionals (HCP) have a role to play in both the prevention and reducing the health impacts of overweight and obesity (Royal College of Physicians policy: public health 2015; BDA Obesity Specialist Group 2018).

Effective health communication positively impacts patient outcomes, if it is sensitive, accurate and honest (Moorhead et al. 2013). Talking to patients about weight loss is known to help to reduce BMl (Pool et al. 2014) and to raise awareness of the health consequences being overweight or obese (Post et al. 2011; Jackson et al. 2013). However, weight loss discussions in healthcare settings are often carried out in an adhoc and non-standardised manner (McHale et al. 2020; Dragomir et al. 2020). HCP report several reasons for not raising the topic of weight, including a lack of training in the sensitive communication skills needed, worries about damaging the patient relationship and a lack of patient motivation (Laidlaw et al. 2016; McPherson et al. 2018).

Current training methods rely on text-driven online learning tools and provide little opportunity for skillsbased practice in the sensitive communication skills required. Virtual reality (VR) is an emerging tool for empathy-focussed skills-based learning. New training approaches for sensitive communication are available through VR (Pan et al. 2016; Real et al. 2017; Pan et al. 2018). There is a gap in the literature new technologies to improve the standard of training for HCP in weight-related communication.

As part of a PhD, a VR-based training tool to improve communication across healthcare settings was developed. Now usability and feasibility testing are required. This paper has been written with the help of PhD supervisors Dr Anne Moorhead, Dr Raymond Bond, Dr Toni McAloon and Prof Huiru Zheng, Ulster University.

\section{RESEARCH QUESTION}

How can a VR-based training tool improve weightrelated communication in healthcare settings? 


\subsection{Aims}

The aims of usability testing are to:

- Assess the usability of a VR-based training tool to improve how HCP communicate about weight in healthcare settings.

- Assess a wizard-of-oz technique for usability testing a VR-based training tool.

The aim of the feasibility study is to:

- Assess the potential feasibility of a VRbased training tool to improve how HCP communicate about weight in healthcare settings.

\section{WIZARD-OF-OZ FOR DESIGNING AND TESTING NEW TECHNOLOGIES}

Wizard-of-oz (Woz) is common research method in human computer interaction studies which has been used to prototype the designs of the future that do not currently exist in the real world. (Dahlbäck et al. 1993). Woz has been used to prototype applications of new technologies, such as VR apps and digital assistant apps (Jonell et al. 2017; Clark et al. 2019). These apps typically include other new technologies such as speech recognition, natural language processing, artificial intelligence and machine learning, which are timeconsuming and complex to develop. Woz facilitates the usability and acceptance testing of intelligent agents without having to fully developed the intelligence. In healthcare settings, Woz has been used to facilitate the design of intelligent agents such as Sim-Sensi Kiosk (DeVault et al. 2014) - a virtual human interviewer for healthcare decision support and an early usability assessment for a conversational agent (Amith et al. 2019) for HPV vaccination.

\section{METHODOLOGY - STUDY DESIGN}

This research is part of a five-phase methodology, progressing in accordance with guidelines laid out in the Medical Research Council (MRC) Framework for Developing and Evaluating Complex Interventions, updated 2008. The MRC framework supports researchers to choose the best design methods for a complex intervention. The usability testing and feasibility study are the final phases of the study. This corresponds to the MRC Framework Feasibility/Piloting phase and Evaluation phase.

The research design of the usability testing and feasibility study uses a mixed method approach, impropriating two validated usability questionnaires, two validated self-assessment communication skills questionnaires and a semi-structured reflective practice interviews with participants.

\subsection{Usability testing}

The purpose of the usability testing is to assess the usability of a VR-based training tool, VITAL-COMS (Figure 1), to improve how HCP communicate about weight in healthcare settings. This study will also include the assessment and analysis of a wizard of oz technique for usability testing.

\subsection{Feasibility study}

The purpose of the feasibility study is to assess the potential of a VR-based training tool, VITAL-COMS, to improve how HCP communicate about weight in healthcare settings.

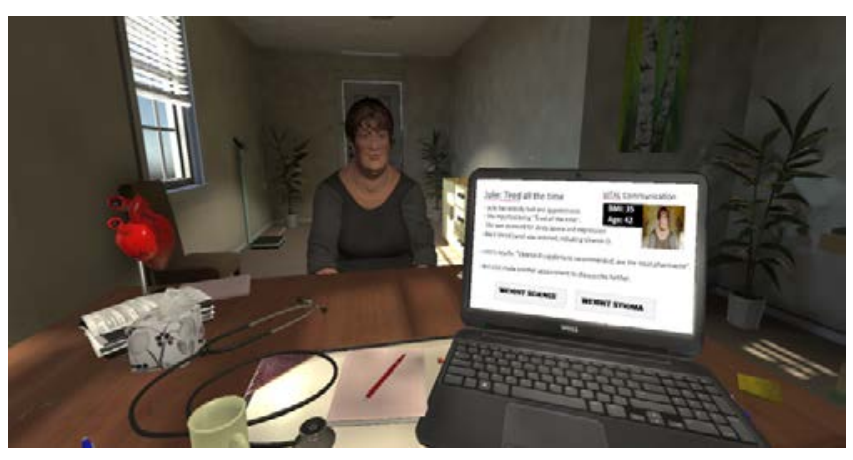

Figure 1: VITAL-COMS Prototype

\section{CONCLUSION}

Studies about how to train HCP to sensitively engage patients in weight-related communication are scarce, despite the global challenge of increasing obesity levels. This study aims to guide $\mathrm{HCP}$ to improve their weight-related communication with patients by using a novel wizard-of-oz experimentation approach within an immersive VR setting.

\section{REFERENCES}

Abdelaal, M., le Roux, C.W. and Docherty, N.G. (2017) Morbidity and mortality associated with obesity. Annals of Translational Medicine, 5(7), 161.

Amith, M., Zhu, A., Cunningham, R., Lin, R., Savas, L., Shay, L., Chen, Y., Gong, Y., Boom, J., Roberts, K. and Tao, C. (2019) Early Usability Assessment of a Conversational Agent for HPV Vaccination. Studies in Health Technology and Informatics, 257, 17-23.

APGO. (2018) The Current Landscape of Obesity Services: A report from the All-Party Parliamentary Group on Obesity, UK. Available at: $\quad$ https://www.aso.org.uk/wp- 
content/uploads/2018/05/APPG-Obesity-ReportMay-2018.pdf (10th January 2019).

BDA Obesity Specialist Group. (2018) Dietetic Obesity Management Interventions in Adults: Evidence Review and Clinical Application. Birmingham: BDA. Available at: https://www.bda.uk.com/regionsgroups/groups/o besity/dietetic_obesity_management_interventio ns_2018 (20th January 2019).

Clark, L., Doyle, P., Garaialde, D., Gilmartin, E., Schlögl, S., Edlund, J., Aylett, M., Cabral, J., Munteanu, C. and Edwards, J. (2019) The state of speech in hci: Trends, themes and challenges. Interacting with Computers, 31(4), 349-371.

Dahlbäck, N., Jönsson, A. and Ahrenberg, L. (1993) Wizard of Oz studies: why and how. In: Wizard of Oz studies: why and how. Proceedings of the 1st international conference on Intelligent user interfaces. , 193-200.

DeVault, D., Artstein, R., Benn, G., Dey, T., Fast, E., Gainer, A., Georgila, K., Gratch, J., Hartholt, A. and Lhommet, M. (2014) SimSensei Kiosk: A virtual human interviewer for healthcare decision support. In: SimSensei Kiosk: A virtual human interviewer for healthcare decision support. Proceedings of the 2014 international conference on Autonomous agents and multiagent systems. , 1061-1068.

Dragomir, A.I., Boucher, V.G., Bacon, S.L., Gemme, C., Szczepanik, G., Corace, K., Campbell, T.S., Vallis, M.T., Garber, G., Rouleau, C., Rabi, D., Diodati, J.G., Ghali, W. and Lavoie, K.L. (2020) An international Delphi consensus study to define motivational communication in the context of developing a training program for physicians. Translational Behavioral Medicine,

Jackson, S.E., Wardle, J., Johnson, F., Finer, N. and Beeken, R.J. (2013) The impact of a health professional recommendation on weight loss attempts in overweight and obese British adults: a cross-sectional analysis. BMJ Open, 3(11), e003693-2013-003693.

Jonell, P., Mendelson, J., Storskog, T., Hagman, G., Ostberg, P., Leite, I., Kucherenko, T., Mikheeva, O., Akenine, U. and Jelic, V. (2017) Machine learning and social robotics for detecting early signs of dementia. arXiv Preprint arXiv:1709.01613,

Laidlaw, A.H., Cecil, J.E. and McHale, C.T. (2016) Direct observation of weight-related communication in primary care: a systematic review. Family Practice, 33(4), 327-345.
McHale, C.T., Laidlaw, A.H. and Cecil, J.E. (2020) Primary care patient and practitioner views of weight and weight-related discussion: a mixedmethods study. BMJ Open, 10(3), e034023.

McPherson, A.C., Knibbe, T.J., Oake, M., Swift, J.A., Browne, N., Ball, G.D.C. and Hamilton, J. (2018) "Fat is really a four-letter word": Exploring weight-related communication best practices in children with and without disabilities and their caregivers. Child: Care, Health and Development, 44(4), 636-643.

Moorhead, S., Coates, V., Gallagher, A., Nolan, G., Murphy, K. and Hazlett, D. (2013) Obesity communication among patients by health professionals: Findings from the Weight Care Project. Health, 5(8C), 100-109.

Pan, X., Collingwoode-Williams, T., Antley, A., Brenton, H., Congdon, B., Drewett, O., Gillies, M.F.P., Swapp, D., Pleasence, P., Fertleman, C. and Delacroix, S. (2018) A Study of Professional Awareness Using Immersive Virtual Reality: The Responses of General Practitioners to Child Safeguarding Concerns. Frontiers in Robotics and $\mathrm{Al}, 5,80$.

Pan, X., Slater, M., Beacco, A., Navarro, X., Bellido Rivas, A.I., Swapp, D., Hale, J., Forbes, P.A.G., Denvir, C., Hamilton, d.C. and Delacroix, S. (2016) The Responses of Medical General Practitioners to Unreasonable Patient Demand for Antibiotics - A Study of Medical Ethics Using Immersive Virtual Reality. Plos One, 11(2), e0146837.

Pool, A.C., Kraschnewski, J.L., Cover, L.A., Lehman, E.B., Stuckey, H.L., Hwang, K.O., Pollak, K.I. and Sciamanna, C.N. (2014) The impact of physician weight discussion on weight loss in US adults. Obesity Research \& Clinical Practice, 8(2), e131-e139.

Post, R.E., Mainous, A.G., Gregorie, S.H., Knoll, M.E., Diaz, V.A. and Saxena, S.K. (2011) The influence of physician acknowledgment of patients' weight status on patient perceptions of overweight and obesity in the United States. Archives of Internal Medicine, 171(4), 316-321.

Royal College of Physicians policy: public health. (2015) Action on obesity: Comprehensive care for all. London: RCP. Available at: https://www.rcplondon.ac.uk/projects/outputs/acti on-obesity-comprehensive-care-all (20th October 2018).

World Obesity Federation. (2019) Global Obesity Observatory. London: World Obesity Federation. Available at: https://www.worldobesitydata.org/ (3rd March 2019). 